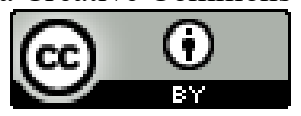

\title{
COTAS PARA NEGROS E INDÍGENAS NA UEMS: PROCESSO HISTÓRICO E POLÍTICO DA CRIAÇÃO AOS DIAS ATUAIS ${ }^{1}$
}

\author{
Maria José de Jesus Alves Cordeiro ${ }^{2}$ \\ Universidade Estadual de Mato Grosso do Sul - UEMS.
}

Resumo: O assunto cotas, considerado uma "medida compensatória" que busca promover o princípio da igualdade, em prol de minorias étnicas e raciais, chegou a Universidade Estadual de Mato Grosso do Sul - UEMS por meio das Leis $n^{\circ} .2 .589$, de 26/12/2002, que dispõe sobre a reserva de vagas para indígenas, e a de $n^{\circ}$. 2.605, de $06 / 01 / 2003$, que dispõe sobre a reserva de $20 \%$ das vagas para negros. O Conselho Superior da instituição regulamentou em $10 \%$ a cota para indígenas, bem como a exigência de ensino médio completo em escola pública para ambas as cotas. Para essas regulamentações houve discussão com lideranças do movimento negro, indígenas e comunidade acadêmica. O primeiro processo seletivo com cotas ocorreu em 2003 e o ingresso em 2004 em trinta e sete cursos de graduação. Neste artigo é feita uma descrição e análise de todo processo histórico e político da criação das cotas, sua implementação e alterações que ocorreram nos processos até os dias atuais com mais de 60 cursos com cotas.

Palavras-Chave: cotas; racismo; ações afirmativas; UEMS.

\section{QUOTAS FOR BLACK AND INDIGENOUS IN UEMS: HISTORICAL AND POLITICAL PROCESS FROM CREATION TO CURRENT DAYS}

Abstract: The issue of quotas, considered as a "compensatory measure" that seeks to promote the principle of equality, in favor of ethnic and racial minorities, began at the State University of Mato Grosso do Sul - UEMS based on Laws No 2.589, of 26/12/2002, which provides for the reservation of vacancies for indigenous, and the Law $\mathrm{N}^{\circ} 2.605$, of $01 / 06 / 2003$, which defines the reserve of $20 \%$ of vacancies for blacks. The institution's Superior Council regulated the quota for indigenous people at $10 \%$, as well as the requirement of complete high school in a public school for both quotas. For these

\footnotetext{
1 Texto original publicado como capítulo de livro na obra: SANTOS, Jocélio Teles (Org). Cotas nas universidades: análises dos processos de decisão. Salvador, CEAO, 2012, sendo reapresentado nesta publicação uma versão atualizada.

${ }^{2}$ Pedagoga com Mestrado e Doutorado em Educação-Currículo pela PUC/SP. Pró-Reitora de Ensino da UEMS. Docente do Programa de Pós-Graduação em Educação/UEMS e curso de Pedagogia. Membro da diretoria da Associação de Investigadores/as Afrolatinoamericanos/as e Caribenhos/as -AINALC. Líder do Grupo de pesquisa GEPEGRE/UEMS/CNPq e membro do Centro de pesquisa em Educação, Gênero, Raça e Etnia - CEPEGRE/UEMS. E-mail: profamaju@gmail.com ; ORCID: https://orcid.org/0000-0003-2044$\underline{8032}$
} 
regulations, discussions were held with leaders of the black movement, indigenous people and the academic community. The first UEMS selection process with quotas took place in 2003 with admission in 2004 to thirty-seven undergraduate courses. This article provides a description and analysis of the entire historical and political process of creating quotas their implementation and changes that occurred in the processes up to the present day with more than 60 courses with quotas.

Keywords: quotas; racism; affirmative action; UEMS.

\section{CUOTAS PARA NEGROS Y INDÍGENAS EN LA UEMS: PROCESO HISTÓRICO Y POLÍTICO DESDE SU CREACIÓN HASTA LOS DÍAS ACTUALES}

Resumen: El tema de las cuotas es considerado una "medida compensatoria" que busca promover el principio de igualdad, a favor de las minorias etnicas y raciales y empezó em la Universidade Estadual de Mato Grosso do Sul - UEMS con las Ley $\mathrm{n}^{\circ}$. 2.589, del 26/12/2002, que prevé la reserva de plazas para indígenas, y la Ley $\mathrm{n}^{\circ}$. 2.605, del $06 / 01 / 2003$, que prevé la reserva del $20 \%$ de las plazas para negros. El Consejo Superior de la institución reguló la cuota para pueblos indígenas en un 10\%, así como el requisito de la educación secundaria completa en una escuela pública para ambas cuotas. Para este reglamento, se llevaron a cabo discusiones con líderes del movimiento negro, indígenas y comunidad académica. El primer processo de selección de UEMS com las cuotas se llevó a cabo en 2003 la admisión en 2004 en los treinta y siete cursos em cursos de grado. Este artículo describe y analiza todo el proceso histórico y político de creación de cuotas, su implementación y cambios que ocurrieron en los procesos hasta la actualidad con más de 60 cursos con cuotas.

Palabras-clave: cuotas; racismo; acciones afirmativas UEMS.

\section{LE SYSTHEME DES QUOTAS POUR LES NOIRS ET LES AUTOCHTONES À UEMS: LE PROCESSUS HISTORIQUE ET POLITIQUE DE LA CRÉATION JUSQU'A NOS JOURS}

Résumé: Le sujet des quotas, considéré comme une «mesure compensatoire » qui cherche à promouvoir le principe d'égalité, en faveur des minorités ethniques et raciales, est appliqué à l'Université de l'État de Mato Grosso do Sul - UEMS à travers les lois $\mathrm{n}^{\text {o }}$. 2589 , du 26/12/2002, en prévoyant la réserve de places pour les peuples autochtones, et $\mathrm{n}^{\mathrm{o}} 2.605$, du 01/06/2003, qui prévoit la réserve de $20 \%$ des places pour les noirs. Le Conseil Supérieur de l'institution a réglementé le quota pour les peuples autochtones à 10 $\%$, ainsi que l'exigence d'avoir étudié tout le cursus secondaire dans une école publique pour les deux formes de quotas. Pour ces règlements, des discussions ont eu lieu avec les leaders du mouvement noir, les peuples autochtones et la communauté universitaire. Le premier processus de sélection avec quotas a eu lieu en 2003 et l'admission en 2004 pour trente-sept cours d'enseignement supérieur. Dans cet article, nous aborderons la description et l'analyse de l'ensemble du processus historique et politique de la création de quotas, de leur mise en œuvre et des changements survenus au cours du processus jusqu'à nos jours, avec plus de 60 cours avec quotas. 
Mots-clés: quotas; racisme; discrimination positive; UEMS.

\section{INTRODUÇÃO}

A Universidade Estadual de Mato Grosso do Sul - UEMS - foi criada pela Constituição Estadual de 1979 e ratificada pela constituição de 1989, conforme os termos do disposto no artigo 48, do Ato das Disposições Constitucionais de 1989, instituídos pela Lei n. 1461, de 20 de dezembro de 1993, com sede e foro na cidade de Dourados-MS. A UEMS tem como mantenedor o Estado de Mato Grosso do Sul, vinculada à Secretaria de Estado de Educação (SED). É regida por Estatuto próprio; Regimento Geral; normas editadas por seus órgãos colegiados e executivos e, no que lhe for pertinente, pelas normas constitucionais, complementares e ordinárias, de edições federais e estaduais.

Como instituição de ensino superior tem por objetivo promover o desenvolvimento integral do ser humano nos diversos campos do conhecimento, em todo o Estado de Mato Grosso do Sul, devendo, para tanto, entre outros, harmonizar a educação superior com a educação básica e profissional, propiciando a incorporação de inovações que contribuam para o desenvolvimento e a melhoria da aprendizagem, e, ainda, interagir com a sociedade num sistema aberto, participativo e cooperativo, catalisador, transformador, facilitador e distribuidor do uso da ciência e da cultura, tendo no Homem o ponto de partida e seu objetivo último.

A Universidade Estadual de Mato Grosso do Sul se diferencia de outras universidades brasileiras por sua proposta de priorização ao atendimento às deficiências dos ensinos fundamental e médio, assim como pela expansão e interiorização do ensino superior, possibilitando aos jovens e adultos egressos de escolas públicas, o acesso e a permanência nos cursos superiores.

As cotas na UEMS foram criadas pelas Leis: n. 2.589, de 26/12/2002, que dispõe sobre a reserva de vagas para indígenas, que teve o percentual de $10 \%$ definido pelo Conselho Universitário - COUNI, e a de n. 2.605, de 06/01/2003, que dispõe sobre a reserva de $20 \%$ das vagas para negros. No Brasil, a UEMS foi a primeira universidade a criar cotas para indígenas e a terceira a criar cotas para negros/as. A UEMS recebeu um prazo de noventa dias para fazer a regulamentação das leis, a partir da criação de cada uma, mas, na prática, precisou do dobro desse tempo, considerando a sistemática adotada pela instituição. A Pró-Reitoria de Ensino - PROE ficou encarregada das ações de 


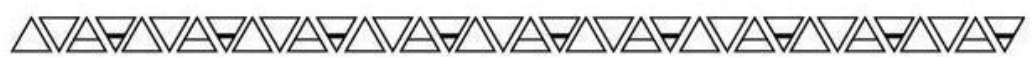

regulamentação e implantação e acompanhamento das cotas, sendo responsável até os dias atuais.

\section{PROCESSO HISTÓRICO E POLÍTICO DAS COTAS NA UEMS}

De acordo com as atas consultadas (CEPE E COUNI, anos de 2003 -2004), a primeira reunião para tratar do assunto, realizada em 18 de março de 2003, foi com a Câmara de Ensino - CE, parte do Conselho de Ensino, Pesquisa e Extensão - CEPE, presidida pela pró-reitora de ensino. Nessa reunião extraordinária, o papel da Câmara era discutir o assunto, ouvir pareceres dos/as conselheiros/as, especialmente de uma docente da UEMS, negra, militante e estudiosa do tema raça e, com base nestes, elaborar parecer conclusivo para o CEPE. A conselheira, a despeito de sua militância e liderança no movimento negro, encaminhou um parecer contrário à implantação das cotas argumentando que:

a) o baixo índice de negros nas universidades era o resultado da falsa abolição dos escravos e do fato que não lhes fora dado o direito à educação, qualificação profissional, moradia e terra para trabalhar;

b) existia indefinição no quesito cor;

c) havia o não-reconhecimento pela sociedade de que na maioria dos brasileiros predomina a essência e a aparência negra;

d) existia a falta de cumprimento da Constituição Brasileira que assegura igualdade para todas as raças;

e) havia a inexistência de oportunidades para os negros.

A conselheira concluiu afirmando que o que precisaria existir seria a igualdade de oportunidade com ética, respeito e dignidade, garantindo, assim, a real qualidade de vida. Outro conselheiro, da área de direito, alertou que a lei, uma vez promulgada, tinha que ser cumprida independente de se querer ou não. Diante dessas considerações foi proposta a realização de debates e fóruns com a comunidade externa, a usuária das cotas. Os conselheiros sentiram-se despreparados para discutir o assunto e solicitaram a formação de uma comissão com a participação do movimento negro, do Conselho Estadual de Direito do Negro, das lideranças indígenas e da Coordenadoria de Políticas para a Promoção da Igualdade Racial - CEPPIR, do Governo do Estado para realizar o 
trabalho. O processo foi retirado de pauta e aprovada uma Comissão de Estudos para aprofundamento da discussão.

Em 04 de abril de 2003, foi realizada uma reunião extraordinária do COUNI, na qual foi discutido o Plano de Desenvolvimento Institucional - PDI e nesse, o item referente aos compromissos da UEMS para o período de 2002 a 2007. O primeiro deles, a interiorização das ações da universidade com vistas à democratização do acesso ao conhecimento. Nesse debate, emergiu a discussão sobre "minorias" e "diferenças" junto à questão das cotas, obrigando os conselheiros do COUNI que ainda não haviam falado sobre o tema a se posicionarem. Muitos deles, inclusive um docente negro, solicitaram registro em ata da sua fala contra as cotas para negros, porém favoráveis à inclusão de pessoas com deficiências.

Vários/as conselheiros/as usaram a fala para "alertar" que o tom deveria ser a qualidade, para que não se produzissem excluídos com diplomas (grifo meu); outros enfatizaram a necessidade de um atendimento "especial" para os índios, pois era um "diferente" e, ainda, houve aqueles que afirmaram que tudo era questão de identidade e a modernização do trabalho didático atenderia a todos. Portanto, nem índios, nem negros, nem deficientes deveriam ser tratados diferentemente.

No Brasil, os negros nunca foram percebidos como iguais, pois as desigualdades socioeconômicas mantêm-nos presos no mais baixo patamar da escala social. Essa inércia os leva a atitude de conformismo, nem sempre conscientes, e à violação das regras sociais (violência), fomentando preconceitos e estigmas. Para D'Adesky, é partindo dessa inferiorização que:

pratica-se toda sorte de discriminações, pelas quais se reduzem de modo eficaz, ainda que muitas vezes inconscientemente, as oportunidades dos membros desse grupo. Mesmo os que conseguem escapar da base da pirâmide social continuam a sofrer com uma imagem depreciativa à qual alguns nem sempre têm força para resistir (D'ADESKY, 2006, p.93).

Os/as negros/as e indígenas precisam resgatar e assumir seus valores, sua beleza, sua cultura e não renunciar a sua identidade étnico-racial. Para Loureiro (2004, p. 92), "[...] não tentar se assemelhar ao modelo branco e reivindicar um lugar ao sol valorizando sua própria etnia ou raça desequilibra ambas as forças que atuam no sistema: a atração e a repulsão", pois é isso que os mantêm presos à periferia do sistema social. Nesse sentido, 
os movimentos sociais ligados ao movimento negro e às lideranças indígenas de Mato Grosso do Sul lutaram e conquistaram as leis que garantem as cotas na UEMS até a presente data. Restou a esta, como instituição, cumprir as determinações legais no sentido de implementar os direitos adquiridos. Assim, deu-se início à trajetória de discussão e regulamentação dessa conquista para os dois grupos.

A comissão criada na Câmara de Ensino, ao iniciar os trabalhos, promoveu o Fórum de Discussão Reserva de vagas para indígenas e negros na UEMS: vencendo preconceitos, nos quatorze municípios onde a UEMS está presente e na sua sede em Dourados-MS, no dia 13 de maio de 2003. Nesse fórum, participaram representantes indígenas, do movimento negro e da sociedade em geral, além da comunidade acadêmica. As mesas foram compostas com pessoas contra e a favor das cotas. Entretanto, em alguns locais não compareceram para o debate pessoas contra cotas para compor mesa.

Baseada nessas discussões a comissão fez um processo de sensibilização na instituição por meio de seminários, palestras, reuniões com coordenadores/as de cursos e gestores/as por, aproximadamente, seis meses. Foram realizadas diversas audiências públicas em vários municípios do estado (Dourados, Ponta Porã, Aquidauana) com a presença da pró-reitora de ensino e do deputado estadual Pedro Kemp (PT), autor da lei de cotas para negros/as. Nessas audiências, buscava-se esclarecer e divulgar os critérios de inscrição nas cotas, que estavam sendo construídos coletivamente, assim como mostrar a preocupação da Universidade com as condições de permanência após o ingresso. $\mathrm{O}$ autor da lei de cotas para indígenas, deputado estadual à época, depois vice-governador e, em 2012 ,prefeito de Dourados-MS e, atualmente, vice-governador novamente, Murilo Zauith, não compareceu a nenhuma audiência ou debate público durante todo processo de regulamentação e implantação das cotas na UEMS.

A Câmara de Ensino voltou a se reunir, no dia 8 de julho de 2003. Desta vez para discutir a oferta de vagas no vestibular e os critérios de inscrição nas cotas, após os resultados de debates e audiências públicas. Estavam presentes à reunião, representantes do movimento negro, Conselho Estadual de Direito do Negro, lideranças indígenas e Coordenadoria de Políticas Para a Promoção da Igualdade Racial - CEPPIR/MS.

As representações indígenas da etnia Guarani alegaram que não se poderia identificar o índio somente pelo documento de identificação indígena (RG), uma vez que se sabia que havia não-indígenas que possuíam documento emitido pela Fundação 
Nacional do Índio - FUNAI. Era importante, mas não o único. Propunham ainda, a autodeclaração em uma das etnias e que, pai e mãe fossem indígenas, bem como morar na aldeia, porque havia entre seu povo muita descrença para com aqueles que moravam fora da aldeia, ou com os que saiam para estudar, porque não mais voltavam para ajudar a comunidade. Também mostraram preocupação com os mestiços que iriam recorrer da decisão.

Os/as indígenas pediram, também, que fosse feita uma prova escrita na língua de cada etnia. Uma conselheira questionou se todos os índios tinham domínio de sua língua, ao que foi respondido que não, informando que, nos dias de hoje, a língua portuguesa é considerada materna, também para eles. Foi, ainda, revelado que a descendência étnica é dada pelo pai entre os Guarani e pela mãe entre os Terena. A discussão ficou acirrada e os representantes negros também se posicionaram a respeito, pois era necessária uma aliança, naquele momento, para não perderem a conquista de política das cotas para negros/as e indígenas.

Um docente membro da Comissão de Estudos apaziguou o debate, solicitando a todos que tomassem cuidado com os critérios para que não viessem a ser injustos. Chamou a atenção para o sentimento de pertença e a possibilidade de tornar tais critérios mais amplos, já que era a primeira experiência de cotas, podendo ser ajustadas com o passar do tempo. Após essas considerações, os/as representantes indígenas resolveram retirar o critério de morar na aldeia, porque muitos indígenas viviam na periferia da cidade de Dourados-MS e de outros municípios. Encetaram-se outras discussões sobre a obrigatoriedade de os/as indígenas formados/as retornarem à aldeia para contribuir com seu povo, discurso abandonado logo depois ao serem lembrados os direitos constitucionais, que garante o ir e vir de cada um, inclusive dos/as indígenas. Contudo, até hoje, se discute este retorno dos/as egressos/as às comunidades.

A reunião, que durou mais de seis horas, teve ainda discussões sobre o número de escolas nas aldeias e a possibilidade de haver ou não candidatos indígenas para preencher o percentual estabelecido; a distância das aldeias até as Unidades Universitárias da UEMS; a sobrevivência destes fora da aldeia; as diferenças culturais etc. Quanto aos negros, os representantes traziam como proposta o fenótipo como critério de ingresso, apesar da discussão sobre a dificuldade de definir raças. No entanto, sabe-se que quem possui pele escura (preta) é mais discriminado, ou seja, o conceito de raça, adotado desde 
o início do processo, foi o social e não o biológico, ou seja, de acordo com Cashmore (2000, p. 454) o termo raça significa: “[...] um grupo de pessoas socialmente unificadas numa determinada sociedade em virtude de marcadores físicos como a pigmentação da pele, a textura do cabelo, os traços faciais, a estatura e coisas do gênero".

Um dos representantes do movimento negro ressaltou a importância do momento, relembrou o genocídio de negros e índios no país e afirmou que a universidade precisava repensar o seu papel de produtora de conhecimento e refletir sobre a formação de cidadãos comprometidos com questões sociais. Declarou também que as cotas não resolviam mazelas, mas forçava repensar papéis e propunha como critérios a renda familiar, o fenótipo, a autodeclaração e o comitê de avaliação. Vários conselheiros foram contra o fenótipo por acreditar na difícil operacionalização. Entretanto, os representantes ali constituídos fecharam a polêmica, reafirmando os critérios de escola pública, fenótipo e autodeclaração, e se colocaram, enquanto instituições e pessoas, à disposição da Universidade para participar do processo de seleção, agindo de forma transparente.

O COUNI voltou a se reunir de forma ordinária, em 17 de julho de 2003. Nessa reunião, embora a pró-reitora de ensino não estivesse presente, foi esclarecido aos conselheiros todo o processo desenvolvido pela Câmara de Ensino/CEPE e Comissão de Estudos no período de março a julho, o resultado das audiências públicas e a minuta de resolução constando os critérios, que seria enviada ao CEPE, conselho competente e com autoridade para aprovação no momento da discussão da oferta de vestibular, prevista para agosto de 2003. Ao COUNI coube aprovar a proposta da Câmara de Ensino que designou $10 \%$ das vagas para indígenas considerando que a lei criada não estabeleceu percentual, conforme Resolução COUNI n. 241, de 17/07/2003.

O debate foi árduo. Muitos/as conselheiros/as contra as cotas, mesmo sabendo que nada mais poderiam fazer para evitá-las. A surpresa ficou por conta da conselheira e representante do Diretório Central de Estudantes (DCE) que se posicionou a favor e solicitou que a Universidade fizesse um trabalho de conscientização dos estudantes sobre o assunto, solicitando a constituição de uma comissão responsável pela organização dessa atividade. Foi votada e aprovada a comissão cujo trabalho principal estava relacionado ao trote cultural dos calouros, sob presidência da Pró-Reitoria de Extensão, Cultura e Assuntos Comunitários. 
Nas discussões levantadas, muitas questões importantes emergiram, como a preocupação com a entrada dos indígenas na universidade, via processo seletivo, porque na visão de alguns e algumas conselheiros/as existia um complicador: os indígenas não pensavam segundo a lógica cartesiana e a universidade é cartesiana. Outro conselheiro representante dos discentes, a despeito do posicionamento do DCE, afirmou que os/as estudantes estavam ofendidos/as pela forma como as cotas foram colocadas na universidade. Em sua opinião, a raça não deveria ser critério para concorrer às cotas, pois o problema estava na formação enquanto estudante. Era preciso um atendimento às pessoas de baixa renda e, no lugar das cotas, o oferecimento de ensino de qualidade, porque o estado demonstrava que não possuía condições, ou não queria atender.

O conselheiro representante da Federação dos Trabalhadores em Educação de Mato Grosso do Sul colocou-se favorável às cotas afirmando que o processo de exclusão não se referia, apenas, ao acesso à universidade, mas inclusive da informação de que poderiam adentrar uma universidade pública. Sugeriu a criação de material explicativo, o uso da mídia como uma forma de fazer esse material chegar até as pessoas, principalmente aos mais carentes, podendo a Universidade contar com a estrutura da Federação, em todo o estado. Foram postas em votação e aprovadas as propostas e a minuta de resolução com o percentual de $10 \%$ para indígenas.

Em 31 de julho de 2003, a reitora como presidente do COUNI, por solicitação da Comissão de Estudos, baixou a Resolução COUNI n. 250 de 31/07/2003, ad referendum, alterando a norma aprovada em 17 de julho de 2003, mais tarde aprovada em plenária do COUNI e, também, no CEPE. A alteração referia-se à cota para negros, determinando que para inscrição nesta, os mesmos deveriam provar sua origem de escola pública ou ser bolsista de escola privada. O critério de bolsista de escola privada foi usado até 2010, quando a UEMS fez adesão em 100\% ao Sistema de Seleção Unificado (SiSU). Com essa adesão foi aprovada a Resolução CEPE/UEMS n. 1045 de 23/09/2010 vigorando a partir de 2010. A Resolução de 2010 revogou a Resolução CEPE-UEMS n. 889 de 16/03/2009, a qual tinha revogado a Resolução de 2004.

Ainda em 2003, o CEPE reuniu-se, ordinariamente, em 14 de agosto, para aprovação da Resolução que instituiu o primeiro vestibular com cotas na UEMS, a qual definia critérios, número de vagas e documentação exigida. Na pauta, o assunto mais comentado no Brasil e nas instituições públicas de ensino superior: cotas e critérios de 
acesso nestas. Na plenária do auditório central da UEMS, mais de trezentas pessoas: docentes, discentes, autoridades municipais, estaduais, legislativas, sindicais, organizações do movimento negro, lideranças indígenas e representantes de instituições educacionais, além de vinte e nove conselheiros/as. Seis conselheiros/as fizeram-se ausentes. Foi proposta pela pró-reitora de ensino e aprovada, autorização para uso da palavra pelos representantes dos/as indígenas e dos/as negros/as, durante a discussão da minuta de resolução proposta pelo Núcleo de Processo Seletivo - NUPS/PROE que tratava dos critérios estabelecidos pela Comissão de Estudos para inscrição nas cotas.

Aberta a palavra aos/as conselheiros/as, o primeiro item questionado foi o uso do critério fenotípico. Uma docente conselheira, sendo bióloga, alegou que esse tipo de classificação não se usa mais, e perguntou quais seriam os parâmetros a serem usados pela comissão de triagem das inscrições. Questionou a declaração de descendência indígena concomitante com o documento de identidade indígena e qual seria o instrumento para encerrar a política de cotas, pois, para ela o procedimento adotado se baseava no modelo norte-americano e o regime acadêmico no Brasil era muito diferente, por isso se preocupava com a qualidade do ensino. Para essa conselheira, o vestibular, apesar de seus defeitos, incoerências e problemas, permitia lidar com todos/as os/as alunos/as que chegavam à sala de aula da mesma forma, enquanto sentia insegurança e receio com o regime de cotas, talvez pela pouca experiência, em relação ao tratamento em sala de aula, se seria especial, diferente.

A obrigatoriedade da foto colorida gerou indagações e discordâncias de parte dos/as conselheiros/as. Dada a palavra à representante da CEPPIR/MS, esta agradeceu e apresentou nomeando as instituições presentes: Grupo Mandela de Fátima do Sul; Associação Rio Brilhantense Senzala e Ação; Fórum de Identidades do Movimento Negro; Conselho Estadual de Defesa dos Direitos do Negro; Grupo Trabalho de Estudos Zumbi de Campo Grande; Grupo Negra Atitude de Dourados; Conselho Nacional da Luta Contra a Discriminação; Associação de Produtores Rurais de Furnas dos Dionísios; Comunidade dos Remanescentes do Quilombo; Conselho Municipal dos Direitos do Negro e Comunidade do Quilombo do Jabaquara.

Em seguida, esclareceu os questionamentos e defendeu que toda ação afirmativa, como o sistema de cotas, é temporária dependendo, apenas, da mudança de comportamento da sociedade. O termômetro para isto seria a mudança dos quadros 
drásticos de desigualdades sociais vigentes no Brasil. Citou pesquisas do Instituto de Pesquisa Econômica Aplicada - IPEA, que mostravam haver em todas as instâncias e camadas da sociedade uma diferença vergonhosa que marcava onde estavam os índios e negros e onde estavam os brancos na sociedade brasileira. Para ela, as cotas tinham o objetivo de trazer esses excluídos para o mesmo patamar dos brancos, e quando isso acontecesse, as cotas se extinguiriam por si mesmas. Lembrou ainda que os/as indígenas e negros/as eram, apenas, vítimas desse processo e os brancos também, mas que negros/as sofriam numa intensidade muito forte, e que dava para sentir na pele, a questão da violência.

Os esclarecimentos continuaram a respeito da terminologia "negros/as", que inclui pretos/as e pardos/as, mas que, no caso da UEMS, a diferença do fenótipo seria observada, pois no Brasil, quanto mais preta for a cor da pele, mais discriminada é a pessoa, cabendo ao/a candidato/a aceitar as regras da Universidade ou recorrer à justiça. Foi reivindicado o direito do/a aluno/a negro/a bolsista de escola privada também concorrer às cotas, conforme aprovado em Resolução do COUNI ad referendum no mês anterior.

As representações indígenas utilizaram a palavra para defender a proposta de Resolução do processo seletivo em discussão e solicitar da UEMS liberdade para formar comissões nas aldeias, com o encargo de fornecer a declaração de descendência, e ainda voltaram à discussão do candidato aldeado e desaldeado, alegando que o indígena que mora na aldeia seria prejudicado, pois o que mora na cidade tinha contato com a televisão, telefone, videogame e outras informações, facilitando o acesso às vagas, ao contrário dos aldeados.

Alguns discursos de conselheiros/as tiveram o tom da demagogia e outros de exacerbação política, sem assumir posição contra, mas com o fito de mostrar para a plenária um comportamento que não os denunciasse ou os deixasse em maus lençóis, como diz o ditado popular. Foi percebido claramente que outros se fizeram surdos e mudos para não se comprometerem. Enquanto isso, um representante negro, de origem quilombola, que se desculpou por não ter estudos como àqueles que ali estavam, dizia ter muito orgulho de estar presente na reunião, participando e defendendo os direitos de muitos, pois sabia que essa sequência de fatos faria mudar o país e que mereciam essa oportunidade. Queria explicar àqueles que receavam o rompimento das bases com essas 
mudanças, que isso não aconteceria, pois eram apenas pedidos de oportunidades. Defendia a entrada de negros/as e indígenas porque acreditava nessa formação e, também, como os/as professores/as ali presentes, não queria que negros/as e indígenas fossem maus profissionais.

Na sequência da reunião, outros representantes fizeram uso da palavra elogiando a universidade, marcando esse dia como histórico para o povo negro e indígena de Mato Grosso do Sul, conclamando os presentes a entender que, com certeza, acertariam em muitas coisas e errariam em outras, podendo corrigir os desacertos no futuro, e instituir políticas de ação afirmativas/cotas não era fazer benevolência a ninguém, mas, minimamente, tentar reparar distorções construídas ao longo dos séculos, incluindo os trezentos anos de escravidão.

As políticas de Ações Afirmativas vigentes no Brasil resultaram de uma longa agenda de lutas e reivindicações do movimento negro. Das teias e laços trilhados contra o racismo antinegro que estrutura as relações sociais, as organizações negras fizeram brotar um conjunto de robustas proposições visando a construção de uma sociedade verdadeiramente fundamentada na diversidade étnico-racial (VIEIRA, 2021, p.361).

Outros assuntos ligados à temática em debate, como o modelo de processo seletivo, nota de corte e mérito, vieram à baila sem, no entanto, obstruir a linha de argumentação adotada para votação dos critérios. Considerada esgotada a discussão, a presidente do CEPE, a reitora, colocou em votação a proposta de inclusão do bolsista de escola privada (já aprovada no COUNI), que foi aprovada. Logo depois, os critérios foram colocados em votação. Pela primeira e talvez única vez, no Conselho de Ensino, Pesquisa e Extensão da UEMS, a aprovação foi por unanimidade, fato que se deu acredita-se, pela quantidade de pessoas presentes, representantes da sociedade e votação nominal, desencorajando vários/as conselheiros/as a se posicionarem contra.

Dessa reunião, saiu aprovada a primeira Resolução CEPE/UEMS n. 382, de 14/8/2003, com os seguintes critérios exigidos para inscrição (depois revogada pela Resolução CEPE/UEMS n. 430, de 30/07/2004, que conservou os mesmos critérios e exigências).

Para os negros:

I - uma foto colorida recente de $5 \times 7 \mathrm{~cm}$;

II - autodeclaração constante na ficha de inscrição; 
III - fotocópia do Histórico Escolar do Ensino Médio ou atestado de matrícula expedida por escola da rede pública de ensino;

IV - declaração da condição de aluno bolsista fornecida por instituição da rede privada de ensino, quando for o caso.

$\mathrm{V}$ - Os candidatos inscritos no percentual de vagas para negros terão as suas inscrições avaliadas por uma comissão instituída pela Pró-Reitoria de Ensino, composta por representantes da UEMS e do Movimento Negro, indicados/as pelo Fórum Permanente de Entidades do Movimento Negro do Mato Grosso do Sul e pelo Conselho Estadual de Defesa dos Direitos do Negro, que as deferirá ou não, por decisão fundamentada, de acordo com o fenótipo do candidato.

VI - os candidatos que tiverem suas inscrições indeferidas concorrerão automaticamente nos setenta por cento referentes às vagas gerais.

Para os indígenas:

I - fotocópia da cédula de identidade indígena (frente e verso);

II - declaração de descendência indígena e etnia, fornecida pela Fundação Nacional do Índio em conjunto com Comissões Étnicas constituídas em cada comunidade.

III - os candidatos que tiverem suas inscrições indeferidas concorrerão automaticamente nos setenta por cento referentes às vagas gerais.

A Comissão composta, conforme mencionado no Inciso V da citação acima, foi constituída pela PROE todos os anos, com publicação de portaria no Diário Oficial do Estado de MS, para proceder à análise dos documentos de inscrição dos/as candidatos/as concorrentes às cotas para negros/as, e, a depender do número de candidatos inscritos, esse trabalho levava cerca de três a cinco dias, processo esse acompanhado pela mídia local com total transparência. Essa forma de avaliação fenotípica de candidatos/as durou até o ano de 2013, quando foi aprovada a Resolução CEPE-UEMS n. 1,373 de 16/10/2013, a qual inclui a criação de bancas presenciais de avaliação fenotípica no processo seletivo. Em 2016, foi aprovada a Resolução CEPE/UEMS n. 1811 de 24/10/2016 revogando as resoluções de 2010 e 2013, que estavam em vigor. As bancas de verificação fenotípica foram criadas sem, no entanto, fixar critérios de avaliação, ficando a cargo de uma comissão geral que incluía os membros das bancas definir estes.

Somente em 2020, com o retorno a gestão da PROE, da mesma pró-reitora da época da criação das cotas, foi levada ao CEPE a criação e aprovação da Resolução CEPE-UEMS n. 2.182, de 02 de outubro de 2020, que alterou o modo de oferta de processo seletivo com retorno do vestibular para 50\% das vagas e revogou a Resolução de 2016. Ainda em 2020, foi aprovada a Resolução CEPE-UEMS n. 2.214, de 04 de dezembro de 2020, e também a Resolução CEPE-UEMS n. 2.215, de 04 de dezembro de 2020, que normatizam as Bancas de Verificação Fenotípica para negros/as, bem como os 
critérios e a documentação para a cota de indígenas. Em 2021, novamente o conselho modificou a normativa de processo seletivo, aprovando a Resolução CEPE-UEMS n. 2.313, de 04 de agosto de 2021.

Contudo, a aprovação dos critérios, ainda em 2003, baseada no fenótipo para os negros e na descendência para os/as indígenas e em vigor até hoje, é uma tentativa da UEMS de colocar em ação o que Munanga (2002) diz a respeito do assunto, na entrevista concedida à Revista Veja on-line, com o título "Chances Iguais", na qual defende que "a questão da raça seja combinada com a questão de classe para o estabelecimento de critérios, para que negros pobres tenham acesso à educação", pois segundo dados do IBGE, no Censo de 2010, $51 \%$ da população brasileira é composta por negros/as de cor preta e parda, enquanto uma minoria frequentava a universidade. Esses dados, por si só, serviram de sustentação para a defesa de qualquer política de ação afirmativa referente aos negros/as. Ação afirmativa:

Esta política é voltada para reverter as tendências históricas que conferiram às minorias e às mulheres uma posição de desvantagem, particularmente nas áreas de educação e emprego. Ela visa ir além da tentativa de garantir igualdade de oportunidades individuais ao tornar crie a discriminação, e tem como principais beneficiários os membros de grupos que enfrentaram preconceitos (CASHMORE, 2000, p.31).

Com base nos estudos apresentados e citados pela Coordenadoria de Políticas para a Promoção da Igualdade Racial do Governo do Estado, ser negro em Mato Grosso do Sul significa, em relação à população branca, ter duas vezes menos chance de concluir o ensino fundamental; ter chances quase nulas de ingressar em cursos superiores como medicina, engenharia ou direito, entre outros; e ter três vezes menos chance de chegar até o final do ensino superior. Significa, ainda, ganhar pouco e em profissões de baixa qualificação. A pele negra significa mais uma barreira no mercado de trabalho, que discrimina trabalhadores pela aparência, ou seja, pelo fenótipo. ${ }^{3}$

Com base em dados como esses é que o Movimento Negro de Mato Grosso do Sul, governo do estado e outras instituições lutaram pela aprovação das leis que

3 Oferta e Demanda de Recursos Humanos em Mato Grosso do Sul. Relatório de pesquisa apresentado em maio de 2001 à Secretaria de Estado de Assistência Social, Cidadania e Trabalho. In: Programa de Superação das Desigualdades Raciais do Governo do Estado de Mato Grosso do Sul. 
estabelecem cotas para negros e indígenas nos cursos superiores da UEMS, como uma ação afirmativa. O uso do critério referente ao fenótipo remete a discussões maiores referentes à raça, identidade, etnicidade, racismo e outros termos.

De acordo com o Parecer CNE/ CP n. 003/2004, elaborado pela conselheira Petronilha Beatriz G. Silva, entende-se por raça a construção social forjada nas tensas relações entre brancos e negros, muitas vezes simuladas como harmoniosas, usado com frequência nas relações sociais brasileiras para informar como determinadas características fenotípicas influenciam, interferem e até mesmo determinam o destino e o lugar social dos sujeitos no interior da sociedade brasileira. O emprego do termo étnico, na expressão étnico-racial, serve para marcar que essas relações tensas devidas a diferenças na cor da pele e traços fisionômicos, se dão, também, em decorrência da raiz cultural plantada na ancestralidade africana, que difere em visão de mundo, valores e princípios das de origem indígena, europeia e asiática.

Por isso, registra-se uma resistência por parte dos/as brancos/as e até de grupos de não-brancos/as, em relação à criação e à implantação de ações afirmativas voltadas para reparações étnico-raciais. É o fruto de uma cultura que vem mantendo o controle social, político e econômico há séculos. Essa resistência tem a ver com a importância dada ao conhecimento como um dos pilares do desenvolvimento humano e o desempenho de papéis que o indivíduo fará durante sua história. Por isso:

Em virtude dos papéis que desempenha, o indivíduo é introduzido em áreas específicas do conhecimento socialmente objetivado, não somente no sentido cognoscitivo estreito, mas também no sentido do "conhecimento" de normas, valores e mesmo emoções (BERGER E LUCKMAN, 1985, p. 106).

Assim, o ingresso no ensino superior, por parte de negros/as e indígenas, caracteriza-se como acesso ao conhecimento identificado pelos autores supracitados e, portanto, funciona como abertura de portas ao acervo total dos conhecimentos acumulados pela sociedade dominante, neste caso, a população branca e a academia. Esse acesso implica, de acordo com Berger e Luckman, "a distribuição social do conhecimento" (1985, p. 107). Com o intento de abalar essa resistência, a UEMS realizou, nos anos de 2004 e 2005, uma Capacitação da Comunidade Universitária para o Processo de Implantação das Políticas de Cotas na Universidade Estadual de Mato Grosso do Sul, em parceria com a CEPPIR/MS e a Fundação Palmares. 
Com o objetivo de capacitar a comunidade acadêmica (docentes, gestores/as, técnicos/as e alunos/as) sobre a importância da implantação de políticas de ações afirmativas (cotas/reserva de vagas no vestibular), as ações realizadas buscaram, em primeiro lugar, sensibilizar os/as participantes que foram convocados/as pela reitoria, com o oferecimento de palestras e debates com intelectuais ativos na discussão nacional sobre ação afirmativa, tais como: prof. dr. José Jorge de Carvalho (Universidade de Brasília -UNB), prof ${ }^{a}$. dr ${ }^{a}$. Petronilha Beatriz Gonçalves e Silva (Universidade Federal de São Carlos -UFSCar e CNE), prof. dr.Wilson Roberto de Mattos (Universidade Estadual da Bahia-UNEB e associação Nacional de pesquisadores/as Negros/as -ABPN), prof. dr. Antônio Carlos de Souza Lima (Museu Nacional - LACED e Trilhas de Conhecimentos), dr. Ivair Augusto dos Santos (Secretaria Nacional de Direitos Humanos -SEDH) e outros/as que estiveram na UEMS, que aqui não nomeamos, mas agradecemos, empreendedores/as de estudos voltados tanto à questão do negro quanto à do indígena. Para os/as discentes, foram realizados quinze seminários, um em cada unidade universitária, com palestrantes ligados ao movimento negro, Conselho Estadual do Direito do Negro e movimento indígena.

\section{DO DEBATE PARA A AÇÃO: VESTIBULAR, SISU E O INGRESSO DE NEGROS/AS E INDÍGENAS COTISTAS NA UEMS}

O primeiro vestibular com cotas, em dezembro de 2003, foi realizado de acordo com a Resolução CEPE-UEMS n. 382, de 14 de agosto de 2003. Nos anos seguintes, 2004 a 2009, o processo seguiu a Resolução CEPE-UEMS n. 430, de 30 de julho de 2004, que revogou a anterior. Essa resolução, além das exigências regulares de documentação, normatizava os critérios de concorrência, aprovação e classificação independentemente da cota, na qual o candidato se inscreveu. ${ }^{4}$ Previa, ainda, os critérios de remanejamento de vagas ociosas em cada regime de cota. A partir do processo seletivo de 2010, a UEMS aderiu $100 \%$ ao Sistema de Seleção Unificado - SISU/MEC. Porém, sobrando vagas após as chamadas feitas pelo SiSU, a UEMS realizava chamadas nos moldes anteriores.

4 Informações retiradas da Resolução CEPE-UEMS n. 430/2004 e do Manual do Candidato ao vestibular elaborado pelo Núcleo de Processo Seletivo - NUPS/PROE e pela Comissão de Processo Seletivo COPESE, da época. 
No tocante às provas realizadas até 2009, a norma citada previa questões objetivas de múltipla escolha em única etapa, divididas em três provas: Conhecimentos Gerais, com 63 (sessenta e três) questões, sendo 7 (sete) de cada área: Língua Portuguesa, Literatura Brasileira, Língua Estrangeira, Matemática, Biologia, Química, Física, Geografia e História; Redação que, juntamente com a prova de Conhecimentos Gerais, atendia, em termos de pontuação, o mesmo modelo da prova do Exame Nacional do Ensino Médio - ENEM; e Conhecimentos Específicos, dividida em três áreas, cada uma com 50 (cinquenta) questões: Área 1 - Ciências Agrárias, Biológicas e da Saúde; Área 2 - Ciências Exatas e Tecnológicas; Área 3 - Ciências Humanas e Sociais. O/A candidato/a fazia essa última prova de acordo com o curso em que estava inscrito.

A norma estabelecia que o candidato que obtivesse índice menor que $20 \%$ (vinte por cento) na prova de Conhecimentos Gerais, nota zero na Redação ou em qualquer uma das disciplinas da prova de Conhecimentos Específicos estava eliminado do processo. Era atribuída nota zero à prova que o candidato não realizava, exceto para os que utilizavam os resultados do ENEM em substituição à nota da prova de Conhecimentos Gerais. O/A candidato/a, mesmo assim podia fazer essa prova, pois o programa utilizado permitia seleção da nota maior - da prova ou do ENEM - para efeito da contagem dos pontos e classificação. A UEMS foi umas das pioneiras no uso da nota do ENEM logo que foi criado.

Quanto à classificação, o processo era realizado por cota e constituído pela soma dos resultados obtidos pelo candidato nas duas provas, obedecendo a uma fórmula específica. Para efeito de classificação, a Redação era considerada como disciplina com pontuação de zero a dez; os totais de pontos para as áreas eram: Redação e Conhecimentos Gerais: 100 pontos; áreas específicas: 100 pontos cada uma. A classificação dos/as candidatos/as era feita por curso, turno e sistema de cota, em ordem decrescente do total de pontos, sendo chamados para matrícula os classificados dentro do limite de vagas.

A partir de 2010 até o processo seletivo de 2019, tempo de adesão em 100\% ao SiSU, as vagas remanescentes dos regimes de cotas, continuaram sendo preenchidas da seguinte forma: as destinadas a negros/as vão para os indígenas e as destinadas aos indígenas para negros/as. Somente após haver chamado todos/as os/as classificados/as negros/as e indígenas de cada curso e não havendo candidatos subsequentes é que as vagas que sobram podem ser destinadas aos/às candidatos/as das vagas gerais. 
Em 2020, foi criado mais um sistema de cotas na UEMS, por meio de lei estadual que destinou $10 \%$ das vagas para moradores do estado com residência a mais de 10 anos. Com isso, em havendo sobra nas vagas de negros/as e indígenas, serão remanejadas para cotistas de MS e, só depois para candidatos/as das vagas gerais. Caso sobre vagas gerais estas são destinadas a negros e indígenas. O/A candidato/a que não efetivava a matrícula ou efetivava e não comparecia às aulas nos 15 (quinze) primeiros dias letivos, tinha sua matrícula cancelada e um novo/a candidato/a a ocupava.

No decorrer dos vários processos seletivos, o número de candidatos que tiveram a inscrição indeferida à cota para negros/as por não apresentarem, na avaliação da comissão responsável (de 2003 a 2012), o fenótipo exigido, sofreu acréscimo, ano após ano, talvez, pelos acontecimentos noticiados em outras instituições de ensino superior que adotaram apenas a autodeclaração e foram obrigadas a aceitarem nas vagas reservadas candidatos/as brancos/as que usaram do subterfúgio da autodeclaração falsa.

As inscrições traziam anexadas fotos dos/as candidatos/as, porém as indeferidas foram aquelas nas quais a foto anexada não apresentava nenhum traço que, aos olhos atentos de negros/as intelectuais e militantes que compunham a comissão, pudesse, pelo menos, plantar dúvidas sobre o fenótipo, pois quando a dúvida era gerada, optava-se pela classificação do/a candidato/a. A prova de que o trabalho desenvolvido pela comissão foi realizado com critério técnico, político e uso do bom senso, pauta-se no fato desta não ter sido questionada processualmente sobre a classificação de candidatos/as como negros/as ou não, durante todos esses anos.

Porém, desde a implantação das bancas presenciais, o número de indeferidos reduziu drasticamente, pois o/a candidato/a ao ser indeferido tem direito a passar em outra banca, chamada recursal. Caso seja indeferido pela segunda vez, perde a vaga.

Além disso, o grande contingente de candidatos/as indeferidos/as por fenótipo, em anos anteriores às bancas, revela outra face do processo seletivo com sistema de cotas para negros/as: a tentativa por parte de não negros/as de burlar as normas estabelecidas e se apropriar do espaço destinado aqueles que, no decorrer da história, estiveram às margens da sociedade do conhecimento, e desta como um todo, sem espaço próprio ou oportunidades iguais de acesso e permanência no sistema educacional, desde a educação infantil ao ensino superior. 
Outro fator de indeferimentos de grande número de candidatos foi a exigência de apresentação de histórico escolar de escola pública ou declaração de bolsista de escola privada. Esse fato, assim como o envio de foto que não atende ao critério do fenótipo, demonstra, claramente, a crença de muitos de que a comissão à época, a exemplos de muitas nesse país, não teria pessoas qualificadas e posicionadas politicamente para arcar com as consequências das decisões tomadas nos indeferimentos. Ledo engano. Pessoas que debalde a pressão reinante em todo país sobre o assunto cotas, não se intimidaram e atuaram dentro do que foi determinado em lei e pelos órgãos colegiados superiores da UEMS. O ministério público, uma única vez, solicitou à Pró-Reitoria de Ensino explicações sobre as características fenotípicas usadas na avaliação dos candidatos. Se houve alguma resposta, não foi dada pela coordenação da comissão, e nem tampouco houve novos questionamentos sobre o assunto.

O espaço acadêmico, como o acesso ao conhecimento científico, constitui-se como um espaço reservado com barreiras que o faz inacessível para alguns grupos ou indivíduos (negros, indígenas, deficientes, etc). Quando esse espaço tem as suas fronteiras flexibilizadas, porém com outras formas de delimitações, dando acesso a determinados grupos excluídos até então (cotas), isso acaba por gerar transições bruscas e causar tensão no grupo ideologicamente majoritário (brancos ricos e pobres). Esse grupo, imediatamente, busca dificultar a movimentação social dos minoritários, através de estratégias que interditem essa passagem, ocasionando a permanência na marginalidade histórica. $^{5}$

No entanto, pode-se afirmar que mesmo com cotas, muito ainda necessita ser feito para garantir a estes grupos, especialmente negros/as e indígenas que compõem a maioria da pobreza no Brasil, uma mudança de realidade, com ascensão social, pois,

A simples inclusão dos jovens das camadas mais pobres da população não é suficiente para mudar a realidade desse segmento da sociedade, torna-se necessário que essa nova configuração da universidade, com maior diversidade social e cultural, comece a trabalhar na perspectiva de questionar s relações sociais que condenam um grande número de pessoas à miséria e à exclusão (LUZ, 2021, P.591).

\footnotetext{
${ }^{5}$ Lewin (apud LOUREIRO, 2004) chama de passagem o fato de as pessoas negarem sua identificação com o seu grupo e se afastarem de suas camadas centrais, permanecendo nas camadas periféricas, em uma tentativa de transpor fronteiras.
} 
A tentativa de burlar o sistema de seleção no regime de cotas e tentar usufruir o espaço reservado aos negros e indígenas é uma das estratégias usadas para transposição das fronteiras agora mais nítidas entre os grupos. Para isso, contam com a invisibilidade e a dificuldade de identificação propalada pela ideologia da mestiçagem e branqueamento que alicerçam as fronteiras étnico-raciais no Brasil. Em suma, jogam com a impossibilidade de saber ou determinar quem é negro/a no Brasil.

O desejo de ascensão social, e também de interdição da ascensão de negros e indígenas, leva esses indivíduos (brancos/as que se autodeclaram negros/a) a assumirem papéis reservados às pessoas que apresentam características fenotípicas estigmatizadas socialmente. Negros/as de ocasião. O objetivo é ocupar o espaço do outro, preservando os privilégios e status atribuídos ao seu grupo, mantendo os/as negros/as e indígenas minados na sua "representação positiva de si mesmos e de seu grupo de pertencimento seu grupo étnico-racial” (LOUREIRO, 2004, p. 61). Essa prática serve à ideologia da exclusão e pode provocar nos/as negros/as e indígenas que não conseguem entrar na universidade um sentimento de inferioridade, que deteriora sua identidade, com a sensação de que não é capaz, pois a chance (cota) foi dada. Desse modo, tudo continuaria como antes na lógica da subalternidade dos/as negros/as e indígenas.

Desde o início, existiam severas críticas ao processo de análise e deferimento das inscrições e ao julgamento feito pela comissão sobre quem apresenta ou não fenótipo de negro/a e fazia jus à concorrência nas vagas destinadas aos/s negros/as. Com a criação das bancas de Verificação Fenotípica, essas críticas diminuíram no âmbito da UEMS. Durante todo tempo de análise por fotos, nenhum candidato/a indeferido/a recorreu solicitando ser avaliado presencialmente como era previsto à época, se apresentando à comissão para provar que a mesma havia se enganado. Após 2013, com as bancas, também não houve processos judiciais nesse sentido. Acredita-se que isso se deve à associação dos critérios de raça e social, transparência do processo e ao trabalho da comissão que sempre foi pública, inclusive indo à televisão e ao rádio para divulgar os critérios e a forma de seleção dos/as inscritos/as.

Na criação das leis de cotas na UEMS e durante o processo de regulamentação, junto aos conselhos, durante todos estes anos, esperava-se o preenchimento das vagas com a participação de outros estados, tanto que o formulário de inscrição foi adaptado com esse objetivo. Todos os/as conselheiros/as e lideranças indígenas tinham consciência 
de que no Estado de Mato Grosso do Sul, embora tendo a segunda maior população indígena do país, não temos escolas de ensino médio nas aldeias em número suficiente para fornecer candidatos/as suficientes para preencher o percentual de vagas estabelecido.

Além do mais, os indígenas do nosso estado já vinham se mobilizando na expectativa de conseguir da UEMS a oferta de cursos de licenciaturas com projetos pedagógicos específicos. A UEMS também foi a primeira do Brasil a oferecer curso Normal Superior específico para indígenas das etnias Guarani Kaiowa e Terenas, em 2000. Portanto, apesar de parecerem poucas (variando por vestibular), 10\% das vagas tornaram-se muitas, em relação ao número de indígenas em condições de concorrer às mesmas. No processo de 2021, por exemplo, são mais 58 cursos presenciais, totalizando 258 (duzentos e cinquenta e oito vagas), metade via vestibular e a outra metade com uso do ENEM.

O não-preenchimento de todas as vagas por parte dos indígenas no sistema de cotas na UEMS pode ter como explicação diversos fatores culturais, sociais e econômicos. A luta para manterem sua identidade os levou a transformações culturais e mudanças diversas, usadas como estratégias de resistência no convívio com a sociedade urbana. A procura pela educação formal é uma dessas mudanças. Contudo, os/as indígenas buscam uma educação que possa atender as diferenças culturais de seus povos e, ao mesmo tempo, fornecer o mesmo conhecimento sistematizado propiciado aos nãoindígenas. Essa educação do não-indígena ao " tratar a diferença das minorias étnicas e/ou econômicas como caso de marginalidade e/ou privação foi o mecanismo criado pelas sociedades para explicar a exclusão ou impor a agregação, valendo-se, para isso, da educação formal." (NASCIMENTO, 2004, p. 21).

Outro fator que contribui, até hoje, para o não preenchimento das vagas diz respeito à localização das unidades universitárias da UEMS, pois algumas, como as de Paranaíba, Cassilândia e Coxim, estão localizadas em regiões distantes das áreas indígenas (mais de $500 \mathrm{~km}$ ), dificultando a permanência/sobrevivência dos/as alunos/as, tanto por questões econômicas (vida na cidade) quanto familiar e cultural, gerando a desistência antes da matrícula, ou até mesmo a não concorrência as vagas.

Todavia, a concorrência é bastante acirrada em outras unidades universitárias, como nas de Dourados, Amambai e Aquidauana, que possuem, no seu limite urbano, aldeias indígenas. Tem-se, ainda, a constatação de interesse por determinadas áreas de 
conhecimento e quase nenhum em outras. A maior procura se dá pelos cursos de Enfermagem, Direito, Ciências Biológicas, Agronomia, Letras, História e Ciência da Computação. Existe também a preocupação e o receio de muitos deles em relação ao ambiente universitário e ao processo de ensino-aprendizagem que não contemplam, com raras exceções, as diferenças culturais e linguísticas dos povos indígenas. Resta ainda, a discriminação e a estranheza por parte de alunos/as não-índios e de professores/as desconhecedores da realidade indígena que bate à sua porta todos os dias, principalmente nos municípios acima citados. Algumas pessoas chegam a dizer que a universidade não é lugar para indígenas. Por conseguinte, não cabe culpar o/a indígena pelo nãoaproveitamento da "oportunidade", pois, ademais, não foram ouvidos no ato da criação da lei, ao contrário dos/as negros/as.

Os/as negros/as, ao adentrarem o ambiente acadêmico e às salas de aulas, além das dificuldades sociais e financeiras, ainda precisam enfrentar o preconceito e a discriminação de colegas e de docentes, com piadas racistas, olhares discriminadores, indiretas e até critérios de avaliação diferenciados. Infelizmente após 18 anos de cotas na UEMS, ainda assistimos atos desse tipo e discursos docentes de que negros/as cotistas entraram pela porta dos fundos. Permanecer nos cursos tronou-se um verdadeiro ato de resistência e de sacrifícios.

\section{CONSIDERAÇÕES FINAIS}

A entrada de negros e indígenas na educação superior, pelo processo de, cotas vem obrigando as universidades a provocarem mudanças no contexto acadêmico e na relação pedagógica, bem como na estruturação do discurso pedagógico. A resistência maior fica evidente na instância dos currículos em prática na academia. Sabe-se que a cultura, a linguagem, as normas e os valores dos grupos dominantes são utilizados como currículo oficial.

É nesta área que precisamos concentrar esforços no sentido de provocar mudanças que contribuam para o fortalecimento do ato de ensinar e aprender, para a permanência dos/as cotistas indígenas que enfrentam, em sala de aula, uma cultura diferente da sua, e dos/as negros/as que enfrentam o racismo. O currículo é e precisa continuar sendo a base de intermediação das diferentes culturas no contexto acadêmico, 
para que nenhum aluno ou nenhuma aluna, negro/a e/ou indígena, sinta-se excluído/a mais uma vez, a exemplo do que já faz a sociedade brasileira.

Na UEMS, após 18 (dezoito) anos de implementação de cotas para negros/as e indígenas, o processo de inclusão ainda é incipiente em alguns cursos, e em vários deles sequer é discutida. Ainda há muito que se fazer na construção de uma nova história para negros/as e indígenas, na UEMS, no estado de Mato Grosso do Sul e no Brasil, rumo a uma sociedade inclusiva de direito e de fato.

Em 2020, ocorreu o retorno do vestibular com $50 \%$ (cinquenta) e os outros $50 \%$ (cinquenta) seleção com uso da nota do ENEM dos últimos 5 anos, devido as mudanças por causa da pandemia, calendários diversos, e a inconsistência do cronograma do ENEM/2020. A partir do ano letivo de 2021, com nova adesão ao SiSU com 50\% (cinquenta) das vagas - ENEM/2021 e 50\% via vestibular, novas análises deverão ser feitas sobre as formas de acesso, os trabalhos das bancas de Verificação Fenotípica, ingresso e permanência, a partir dos dados institucionais.

\section{REFERÊNCIAS BIBLIOGRÁFICAS}

BRASIL. Parecer CNE/CP 003/04. Brasília: MEC/CNE, 2003.

BERGER, P; LUCKMANN, T. A construção social da realidade. 14.ed. Petrópolis: Vozes, 1985.

CASHMORE, Ellis. Dicionário das relações étnicas e raciais. Tradução Dinah Kleve. São Paulo: Summus, 2000.

CORDEIRO, M.J.J.A. Cotas para negros e indígenas na UEMS: processo histórico e político. In: SANTOS, Jocélio Teles (Org). Cotas nas universidades: análises dos processos de decisão. Salvador, CEAO, 2012.

D'ADESKY, JACQUES. Anti-racismo, liberdade e reconhecimento. Rio de Janeiro: Daudt, 2006.

MATO GROSSO DO SUL. Lei n. 2.589, de 26/12/2002, dispõe sobre reserva de vagas na UEMS para indígenas. Campo Grande - MS, 2002.

MATO GROSSO DO SUL. Lei n. 2.605, de 06/01/2003, dispõe sobre reserva de $20 \%$ das vagas da UEMS para negros. Campo Grande - MS, 2003.

MATO GROSSO DO SUL. Lei n. 1.461, de 20 de dezembro de 1993. Criação da Universidade Estadual de Mato Grosso do Sul. Campo Grande, 1993.

INSTITUTO BRASILEIRO DE GEOGRAFIA E ESTATÍSTICA (IBGE). Censo demográfico 2010. Brasília, DF: IBGE, 2010. Disponível em: 
〈https://indigenas.ibge.gov.br/images/pdf/indigenas/verso_mapa_web.pdf> Acesso em: 20 mar. 2020.

LOUREIRO, Stefânie Arca Garrido. Identidade étnica em re-construção: a ressignificação da identidade étnica de adolescentes negros em dinâmica de grupo na perspectiva existencial humanista. Belo Horizonte: Editora O Lutador, 2004.

LUZ, J. A. G. Sobre a política de ações afirmativas: onde estamos? Revista ABPN, v.13, n.37, junho-agosto 2021, p.582-594.

NASCIMENTO, Adir Casaro. Escola indígena: palco das diferenças. Campo Grande - MS: UCDB, 2004.

UNIVERSIDADE ESTADUAL DE MATO GROSSO DO SUL. Resolução CEPE, n. 382 de 14/08/03. Dourados-MS, 2003.

UNIVERSIDADE ESTADUAL DE MATO GROSSO DO SUL. Resolução CEPE, n. 430 de 30/07/04. Regulamenta os critérios de inscrição para candidatos às Cotas de Negros e Indígenas. Dourados-MS, 2004.

UNIVERSIDADE ESTADUAL DE MATO GROSSO DO SUL. Resolução CEPE-UEMS n. 889 , de 16/03/2009, que aprova o regulamento do processo seletivo de candidatos aos cursos de graduação, da Universidade Estadual de Mato Grosso do Sul. Dourados-MS, 2009.

UNIVERSIDADE ESTADUAL DE MATO GROSSO DO SUL. Resolução CEPE-UEMS, n. 1,045 , de 23/09/2010, que aprova o regulamento do processo seletivo de candidatos aos cursos de graduação, da Universidade Estadual de Mato Grosso do Sul. Dourados-MS, 2010.

UNIVERSIDADE ESTADUAL DE MATO GROSSO DO SUL. Resolução CEPE-UEMS, n. 1,373 , de 16/10/2013, que aprova critérios para ingresso de candidatos aprovados pelo regime de cotas para negros no Processo Seletivo para os Cursos de Graduação da UEMS. Dourados-MS, 2013.

UNIVERSIDADE ESTADUAL DE MATO GROSSO DO SUL. Resolução CEPE-UEMS, n. 1811 , de 24/10/2016 que aprova o regulamento do processo seletivo de candidatos aos cursos de graduação da Universidade Estadual de Mato Grosso do Sul e dá outras providências. DouradosMS, 2016.

UNIVERSIDADE ESTADUAL DE MATO GROSSO DO SUL. Resolução CEPE-UEMS, $\mathrm{n}$ 2.182 , de 02 de outubro de 2020, que aprova o Regulamento e a oferta de vagas do Processo Seletivo de candidatos para ingresso em 2021 nos cursos de graduação da Universidade Estadual de Mato Grosso do Sul e dá outras providências. Dourados-MS, 2020.

UNIVERSIDADE ESTADUAL DE MATO GROSSO DO SUL. Resolução CEPE-UEMS, $n$. 2.313 , de 04 de agosto de 2021, que aprova oferta de vagas no processo Seletivo para ingresso de candidatos em 2022, nos cursos de graduação da Universidade Estadual de Mato Grosso do Sul e dá outras providências. Dourados-MS, 2021.

UNIVERSIDADE ESTADUAL DE MATO GROSSO DO SUL. Resolução CEPE-UEMS, $n$. 2.214 , de 04 de dezembro de 2020, que aprova a regulamentação das bancas e procedimentos de Verificação Fenotípica dos candidatos negros (pretos e pardos), presencial e/ou virtual, para fins de preenchimento das vagas reservadas no sistema de cotas para negros da UEMS. DouradosMS, 2020. 
UNIVERSIDADE ESTADUAL DE MATO GROSSO DO SUL. Resolução CEPE-UEMS, n. 2.215 , de 04 de dezembro de 2020, que aprova os critérios e procedimentos de ingresso e matrícula de candidatos indígenas nas vagas reservadas no sistema de cotas para indígenas nos cursos de graduação da UEMS. Dourados-MS, 2020.

UNIVERSIDADE ESTADUAL DE MATO GROSSO DO SUL. Atas do Conselho Universitário - COUNI. Dourados - MS, Anos de 2003 e 2004.

UNIVERSIDADE ESTADUAL DE MATO GROSSO DO SUL. Atas do Conselho de Ensino, Pesquisa e Extensão - CEPE. Dourados - MS, Anos de 2003 e 2004.

UNIVERSIDADE ESTADUAL DE MATO GROSSO DO SUL. Atas da Câmara de Ensino Conselho de Ensino, Pesquisa e Extensão - CEPE. Dourados - MS, Anos de 2003 e 2004.

UNIVERSIDADE ESTADUAL DE MATO GROSSO DO SUL. Resolução COUNI, n. 241, de 17/07/2003, dispõe sobre a oferta das vagas em regime de cotas dos cursos de graduação da UEMS. Dourados - MS, 2003.

UNIVERSIDADE ESTADUAL DE MATO GROSSO DO SUL. Resolução COUNI n. 250 de 31/07/2003, "ad-referendum", que altera a redação da alínea "b" do art. $1^{\circ}$ da Resolução COUNI n 241/03. Dourados-MS, 2003.

VIEIRA, Cleber Santos. Políticas de ações afirmativas: subsídios para o debate de aprimoramento. Revista ABPN, v.13, n.36, março-maio 2021, p.361- 364.

Recebido em: 01/10/2021

Aprovado em: 20/11/2021 